\title{
Novas técnicas de reometria aplicadas a suspensões cerâmicas
}

\section{(Novel rheometric techniques applied to ceramic suspensions)}

\author{
R. D. dos Anjos, R. Salomão, V. C. Pandolfelli \\ Departamento de Engenharia de Materiais - DEMa \\ Universidade Federal de S. Carlos - UFSCar \\ Rod. Washington Luiz, km 235, C.P. 676, S. Carlos, SP 13565-905 \\ renataanjos@polvo.ufscar.br,vicpando@power.ufscar.br
}

\begin{abstract}
Resumo
Suspensões cerâmicas com adequado comportamento reológico são imprescindíveis para a aplicação, adequação do processamento e otimização das propriedades finais dos produtos. No entanto, o uso de técnicas de reometria para análise de suspensões cerâmicas foi pouco explorado na literatura, quando comparado a outros sistemas, tais como polímeros fundidos. Desse modo, pretendese demonstrar que o emprego de técnicas mais modernas de reometria permite uma nova compreensão desses materiais e das interações entre seus componentes. Neste trabalho foi estabelecida uma metodologia de análise para sistemas cerâmicos tendo como objeto de pesquisa uma suspensão de alumina e sol de sílica. Foi realizada uma série de medidas de viscosidade ( $\eta$ ), módulos de armazenamento (G') e de perda (G”) e de força normal (Fn), cujos resultados servirão de base para estudos posteriores no mesmo sistema, visando aplicação em concretos refratários.
\end{abstract}

Palavras-chave: reometria, suspensões cerâmicas, sol de sílica.

\begin{abstract}
Ceramic suspensions with suitable rheological properties are essential on application, process control and optimization of end products and properties. Nevertheless, the use of rheometric techniques to analyze such suspensions has been scarcely studied when compared to other systems, such as molten polymers. Therefore, in the present work, novel rheometric techniques will be presented which can allow a further understanding regarding these materials and the interaction among their components. A systematic study applying these techniques was established and the viscosity, storage modulus, loss modulus and normal force measurements were evaluated in a ceramic suspension containing alumina and silica sol. These results will be the fundaments for further studies, aiming their application on refractory castables.

Keywords: reometry, ceramic suspensions, silica sol.
\end{abstract}

\section{INTRODUÇÃO}

Suspensões líquido/sólido são caracterizadas por um conjunto de partículas distribuídas de forma relativamente uniforme através de um meio líquido, sem que haja, ao longo do tempo, dissolução significativa do material particulado [1]. Suspensões cerâmicas com propriedades reológicas adequadas são imprescindíveis na aplicação, adequação do processamento e otimização das propriedades finais dos produtos. A compreensão da reologia de suspensões cerâmicas é primordial para a eficiente homogeneização das matérias-primas que a compõem, uma vez que afeta diretamente o comportamento durante a mistura e as suas características de bombeamento e transporte, como é o caso, por exemplo, de pastas para serigrafia, tintas e concretos refratários monolíticos [2]. No entanto, o uso de técnicas de reometria para caracterização dessas suspensões cerâmicas é pouco explorado na literatura, quando comparado a outros sistemas, como alimentos, tintas e polímeros.

Como possuem propriedades muito distintas dos outros sistemas, as técnicas de caracterização reológica usuais não são, necessariamente, as mais adequadas para análise desses materiais. Além disso, as publicações referentes a suspensões cerâmicas, em geral, abordam a reologia como método de controle de uma variável dentro de um processo, e não como o foco do trabalho. Devido a isso, faz-se necessário o emprego de técnicas mais modernas de reometria para o estudo de sistemas cerâmicos, permitindo assim uma nova compreensão desses materiais e das interações entre seus componentes.

O objetivo desse trabalho foi estabelecer uma metodologia de análise adequada para sistemas cerâmicos através de um estudo sistemático dessas novas técnicas. Foi estudada uma suspensão cerâmica de alumina e sol de sílica, uma vez que esse agente ligante tem sido apontado como alternativa aos cimentos de aluminato de cálcio utilizados em concretos refratários devido a sua capacidade de gelificação [3].

Nesse trabalho foi realizada uma série de medidas de viscosidade $(\eta)$, módulos de armazenamento (G') e de perda (G”) e de força normal (Fn), cujos resultados servirão de base para estudos posteriores no mesmo sistema, visando aplicação em concretos refratários. O ensaio denominado dinâmico ou oscilatório, submete as amostras a tensões ou deformações oscilatórias (dependendo do modo de operação 
do reômetro), aplicadas segundo uma função senoidal do tempo. Esse teste permite uma diferenciação entre as respostas viscosa e elástica do material. Elas são expressas pelo módulo de armazenamento ou elástico (G'), que indica quanto da tensão aplicada pode ser temporariamente armazenada e instantaneamente recuperada; e pelo módulo de perda ou viscoso (G'), que é associado à energia utilizada para iniciar o fluxo viscoso, irreversivelmente transformada em calor [4]. Outro tipo de ensaio pode determinar a força normal (Fn) gerada em um corpo em virtude de uma deformação elástica imposta. É uma medida da elasticidade do sistema [5], assim como G', mas que pode fornecer informações adicionais.

\section{MATERIAIS E MÉTODOS}

\section{Matérias-primas}

A maioria dos ensaios foi realizada em suspensões base de alumina e sol de sílica com 56,57 \%v de sólidos (exceções são descritas na discussão). Um reômetro rotativo RS300 (Thermo Haake - Alemanha), um misturador de bancada (Ética Equipamentos Científicos S.A.), um ultrasom Unique UltraSonic (Thornton Unique) e uma câmara climática (Vötsch, modelo 20-20) foram os equipamentos utilizados. As matérias-primas utilizadas foram: alumina A17NE (Almatis EUA), sol de sílica Bindzil (Nalco). Como dispersantes utilizou-se o ácido cítrico anidro PA (Synth), o polietilenoglicol FS10 (SKW Polymers), o policarboxilato
FS20 (SKW Polymers) e o polimetacrilato de sódio Darvan 7S (R. T. Vanderbilt Company, Inc.) e, adicionalmente, um agente acelerador da reação de gelificação do sol de sílica , o óxido de magnésio grau PA (Synth) [6].

\section{Homogeneização das suspensões}

A homogeneização de todas as suspensões para esse estudo foi realizada em um misturador de bancada na velocidade de $40 \mathrm{rpm}$.

\section{Ensaios de otimização da dispersão}

Os ensaios de dispersão foram realizados a $25{ }^{\circ} \mathrm{C}$, utilizando-se cilindro coaxial, sob taxa de cisalhamento constante de $50 \mathrm{~s}^{-1}$ durante $30 \mathrm{~s}$ ou sob variação da taxa (0 a $50 \mathrm{~s}^{-1}$ ) para as amostras submetidas ao ultra-som.

\section{Ensaios de gelificação}

Os ensaios de gelificação são ensaios oscilatórios realizados no modo de operação com controle de tensão, com freqüência e tensão constantes de $1 \mathrm{~Hz}$ e $1 \mathrm{~Pa}$, respectivamente. Os sistemas de medidas utilizados foram as ferramentas placa-placa serrilhada acoplada a um dispositivo protetor (para evitar secagem) e vane, através dos quais se obtêm medidas de G'e G' em função do tempo. A superfície da suspensão, em todos os ensaios com a ferramenta vane, foi recoberta com uma camada de óleo para evitar secagem.

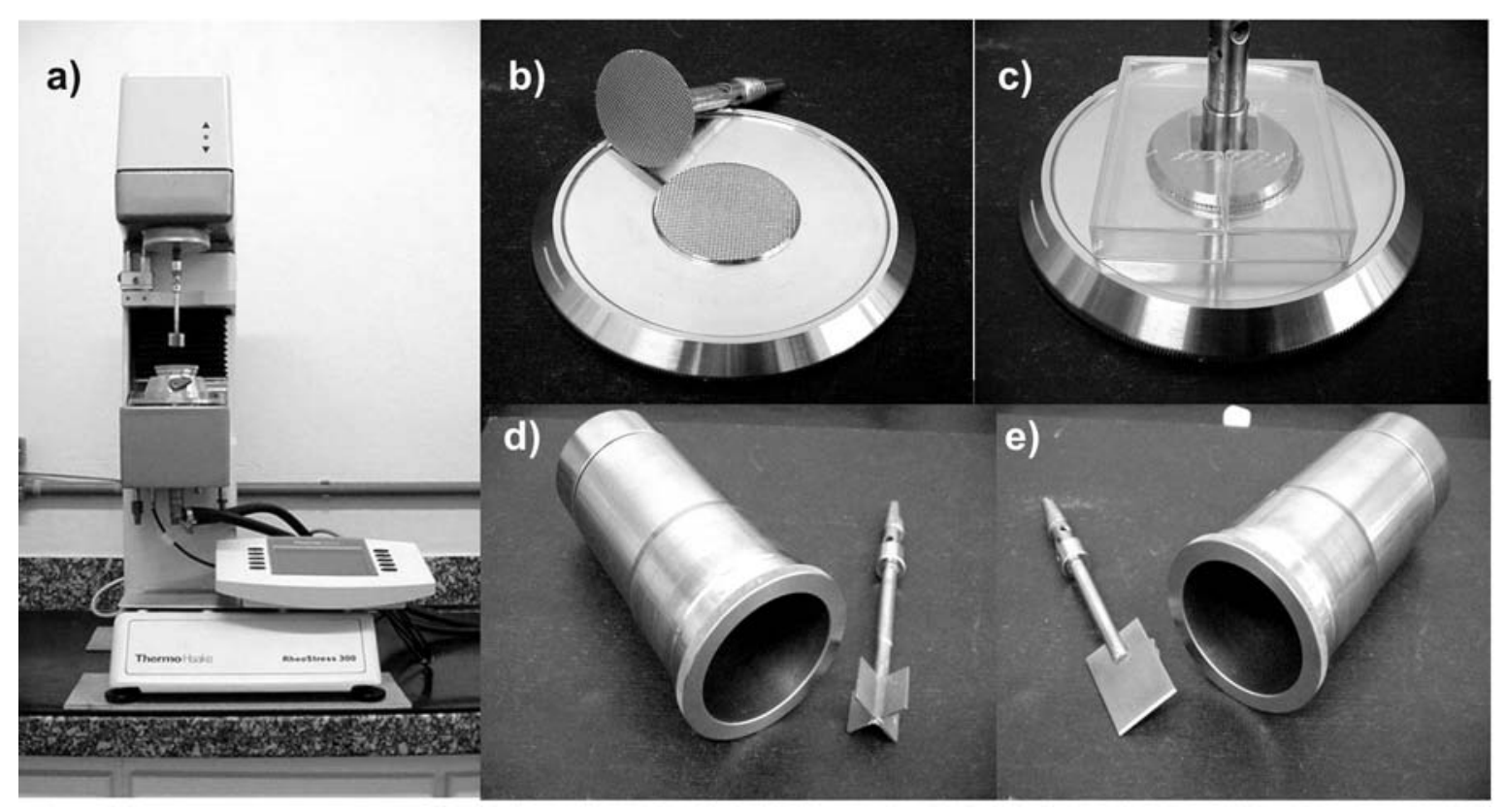

Figura1: Equipamento e ferramentas utilizados; a) reômetro RS300, b) placa-placa serrilhada, c) placa-placa serrilhada com protetor, d) vane e e) indentador em forma de lâmina.

Figure 1: Equipment and tools: a) RS300 rheometer, b) serrated plate, c) serrated plate with protetor device, d) vane and e) blade-shape tool. 


\section{Ensaios de força normal}

Os ensaios de força normal consistem na medida da resistência do material a uma deformação imposta, ou seja, detectam a força normal gerada pela amostra em resposta à penetração da ferramenta, um indentador em forma de lâmina (Fig. 1e).

$\mathrm{O}$ equipamento, as ferramentas e o dispositivo utilizados nos ensaios são apresentados na Fig. 1.

\section{RESULTADOS E DISCUSSÃO}

Uma suspensão cerâmica homogênea é obtida quando suas partículas são totalmente individualizadas. A aplicação de ultra-som é comumente utilizada na desaglomeração por meio do fornecimento de energia vibracional às partículas, influindo diretamente na determinação do teor de aditivos a serem utilizados. Sendo assim, testes preliminares de defloculação foram realizados para verificação da influência do ultra-som utilizando-se FS10 como dispersante. A Fig. 2 ilustra os resultados para amostras submetidas ao ultra-som após mistura por diferentes intervalos de tempo.

Verifica-se que a viscosidade diminui com o aumento do tempo de aplicação do ultra-som, o que indicaria a obtenção de uma melhor dispersão. No entanto, outro fator pode ser responsável por esse decréscimo: aumento na temperatura da suspensão provocado pelo ultra-som, chegando a uma variação de até $29^{\circ} \mathrm{C}$ para uma aplicação por $3 \mathrm{~min}$. Apesar das diferenças observadas com o uso do ultra-som, conclui-se que esse processamento não é adequado para os estudos do sistema alumina-sol de sílica, visto que um mínimo aumento na temperatura pode influir na cinética de

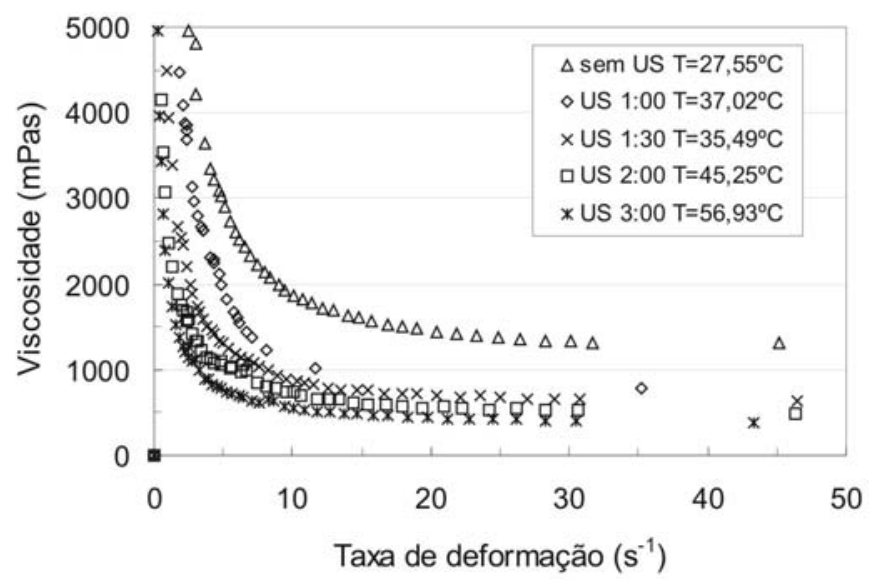

Figura 2: Viscosidade em função da taxa de deformação para suspensão de alumina e sol de sílica com adição de $1,09 \mathrm{mg} / \mathrm{m}^{2}$ de FS10, com aplicação de ultra-som durante diferentes intervalos de tempo (T: temperatura da suspensão).

[Figure 2: Viscosity as a function of shear rate for alumina and silica sol suspension with $1,09 \mathrm{mg} / \mathrm{m}^{2}$ of FS10, under ultra-sound application along different time (T: suspension temperature).] gelificação desse material. Nas amostras que foram sujeitas à aplicação de ultra-som, foi observada ainda a formação de uma película na superfície da suspensão, indicativo da ocorrência de secagem.

A Fig. 3 apresenta ensaios de dispersão da suspensão base (alumina e sol de sílica) com diferentes aditivos.

Observa-se que a viscosidade das suspensões de alumina e sol de sílica pode ser reduzida, embora não muito, com aditivos dispersantes. Adicionalmente, verifica-se que o sol de sílica sozinho não cumpre o papel de dispersante para alumina nesse sistema, como citado em literatura para outros materiais [3]. Dentre os vários dispersantes utilizados, o FS20 foi o mais efetivo para esse sistema.

Dois tipos de ferramenta podem ser usados em ensaios oscilatórios: a placa-placa e a vane (Fig. 1a e 1d). Como a primeira é mais amplamente utilizada, foi escolhida para

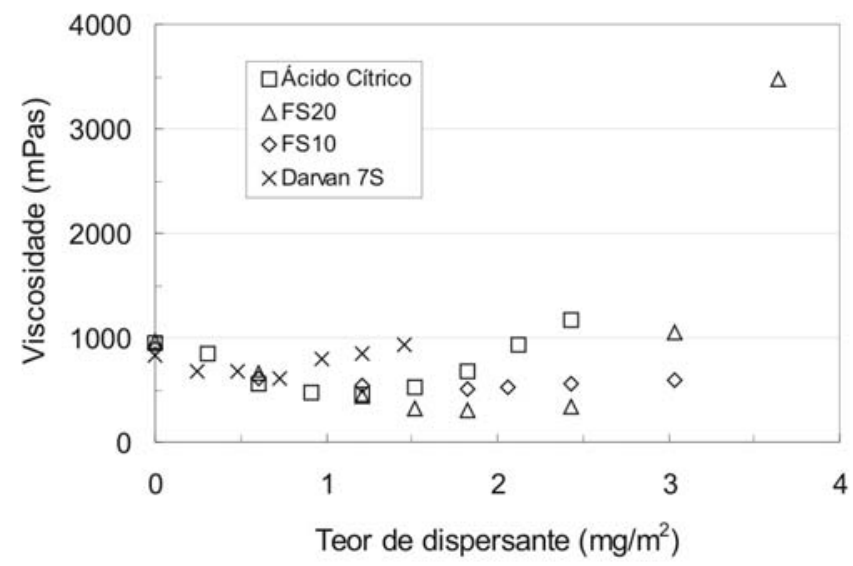

Figura 3: Viscosidade em função do teor de dispersante para suspensões de alumina e sol de sílica.

[Figure 3: Alumina and silica sol suspension viscosity as a function of dispersant content.]

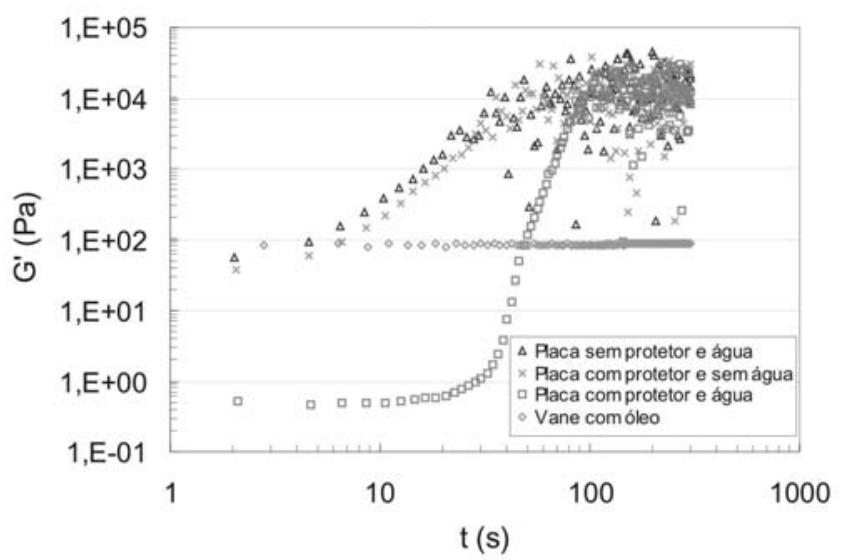

Figura 4: G' em função do tempo para suspensões de alumina e água destilada com diferentes configurações experimentais $\left(50^{\circ} \mathrm{C}\right)$.

[Figure 4: $G$ ' as a function of time for alumina and distilled water suspensions with different experimental configurations $\left.\left(50^{\circ} \mathrm{C}\right).\right]$ 


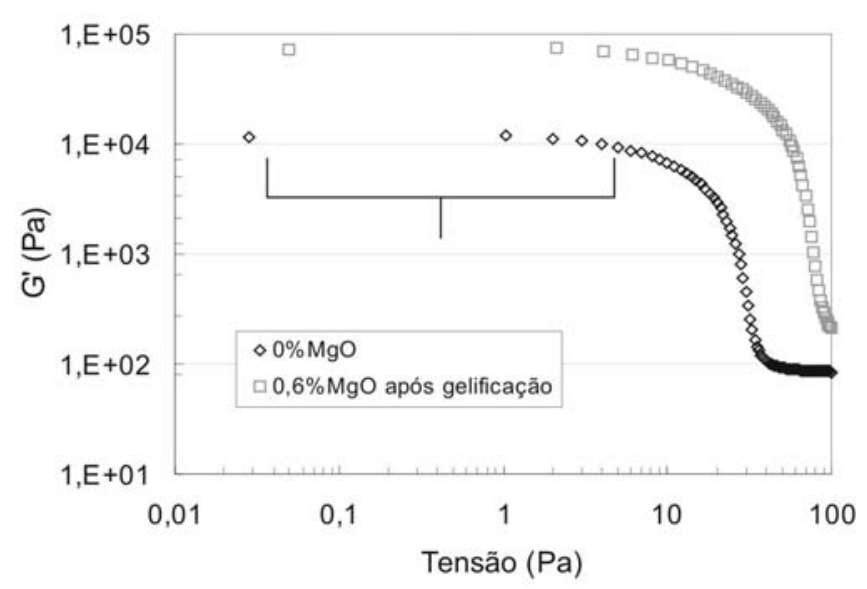

Figura 5: G' em função da tensão aplicada para suspensões com e sem adição de $\mathrm{MgO}$.

[Figure 5: G' as a function of applied tension for suspensions with and without $\mathrm{MgO}$.]

realização de testes preliminares para padronização dos procedimentos de ensaios. Para tanto, foram ensaiadas suspensões com 56,45 vol.\% de sólidos de alumina e água destilada, por não apresentarem nenhuma reação ao longo do tempo, facilitando a detecção da ocorrência de secagem ou absorção de umidade do meio.

A série de ensaios (freqüência e tensão constantes de 1 $\mathrm{Hz}$ e $0,5 \mathrm{~Pa}$, respectivamente) foi realizada, respeitando a seguinte metodologia: quantidade de amostra preenchendo totalmente a placa, temperatura de ensaio constante de 50 ${ }^{\circ} \mathrm{C}$ e variação das condições de umidade próxima à amostra. Para controle dessa variável, foi utilizado um dispositivo de proteção e gotas de água destilada ao redor do sensor (Fig. 1c) a fim de saturar o ambiente e evitar perda de água da amostra, ou seja, evitar secagem. Segue a relação das combinações entre os experimentos realizados: i) sem a utilização de protetor e água, ii) com protetor e sem água e iii) com a utilização de protetor e água. Observam-se os resultados na Fig. 4, juntamente com uma curva obtida em ensaio nas mesmas condições com a ferramenta vane e a superfície da suspensão recoberta com óleo, a titulo de comparação.

Para ferramenta placa-placa, mesmo com a utilização do dispositivo de proteção e água para saturar o ambiente, houve secagem do material, verificada pelo aumento de G'. Aárea de contato das placas com a suspensão é muito grande, favorecendo a secagem, mesmo com esses cuidados. Com a utilização da vane, que permite o recobrimento da amostra com óleo, esse problema é definitivamente evitado. Além disso, essa ferramenta permite a análise de uma quantidade muito maior de amostra, portanto mais representativa, e proporciona uma preparação mais rápida para o ensaio, uma vez que a colocação da amostra é facilitada. Portanto, essa foi a ferramenta utilizada em todos os ensaios oscilatórios. A diferença nos valores iniciais de $G^{\prime}$ das suspensões

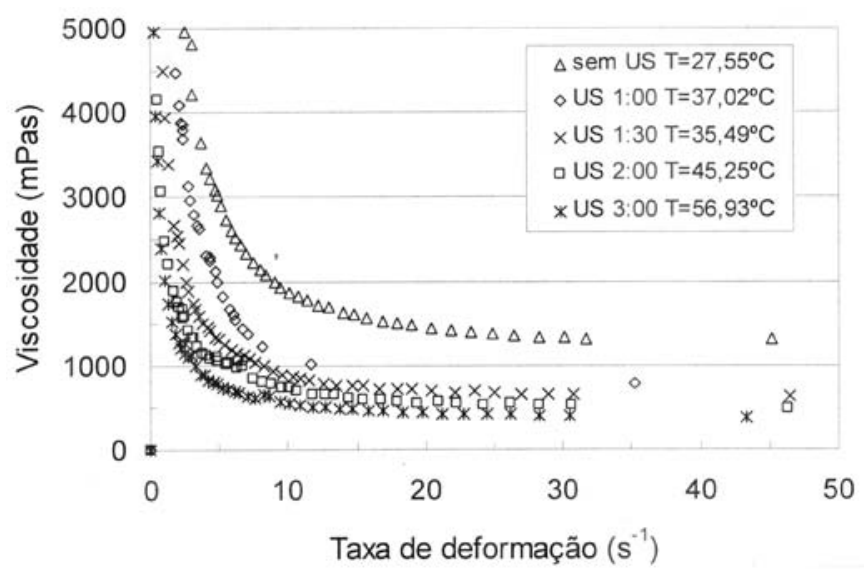

Figura 6: Suspensões de alumina e sol de sílica com diferentes teores de $\mathrm{MgO}$ à $25^{\circ} \mathrm{C}$; a) $\mathrm{G}^{\prime}$ em função do tempo e b) $\mathrm{G}$ ” em função do tempo.

[Figure 6: Alumina and silica sol suspensions with different $\mathrm{MgO}$ content at $25^{\circ} C$; a) $G$ ' as a function of time and $\left.b\right) G$ " as a function of time.]

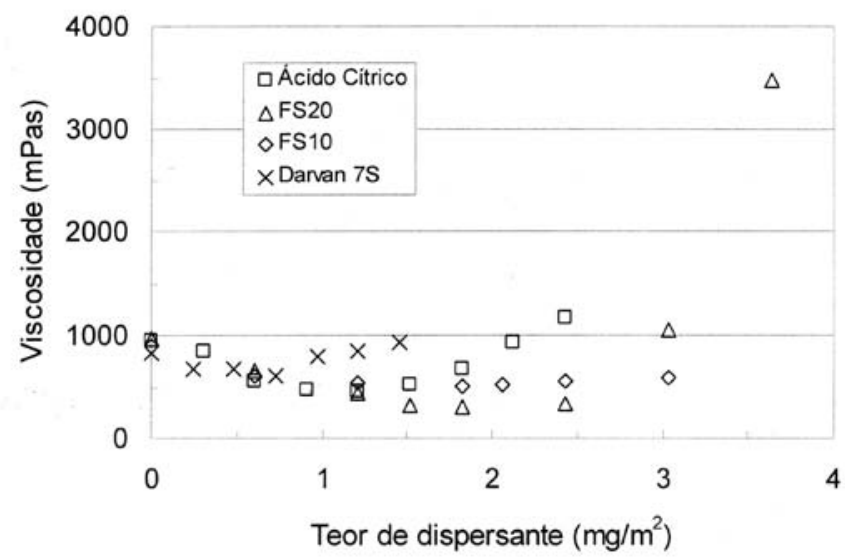

Figura 7: Suspensões de alumina e sol de sílica com adição de 0,3 peso\% de $\mathrm{MgO}$ em diferentes temperaturas; a) G' em função do tempo e b) G" em função do tempo.

[Figure 7: Alumina and silica sol suspensions with $0.3 \mathrm{wt} \% \mathrm{MgO}$ at different temperatures; a) $G$ ' as a function of time and b) $G$ ” as a function of time.]

ensaiadas na placa deve-se à secagem instantânea das amostras i) e ii); já a diferença entre os ensaios com placa e vane deve-se à quantidade de amostra e geometria das ferramentas.

Para a realização de medidas dos módulos de armazenamento e de perda, G'e G', respectivamente, é necessário que o material em análise seja solicitado dentro de seu regime elástico, ou seja, que não sofra ruptura de sua estrutura. Assim, deve-se estabelecer a faixa de tensão na qual o material obedece esse regime (através de um ensaio de varredura de tensão de 0,01 até $100 \mathrm{~Pa}$ em freqüência de $1 \mathrm{~Hz}$ em temperatura controlada de $25^{\circ} \mathrm{C}$ ). A Fig. 5 apresenta o ensaio realizado em duas suspensões de alumina e sol de sílica com 62,48 vol.\% de sólidos, $0,26 \mathrm{mg} /$ 


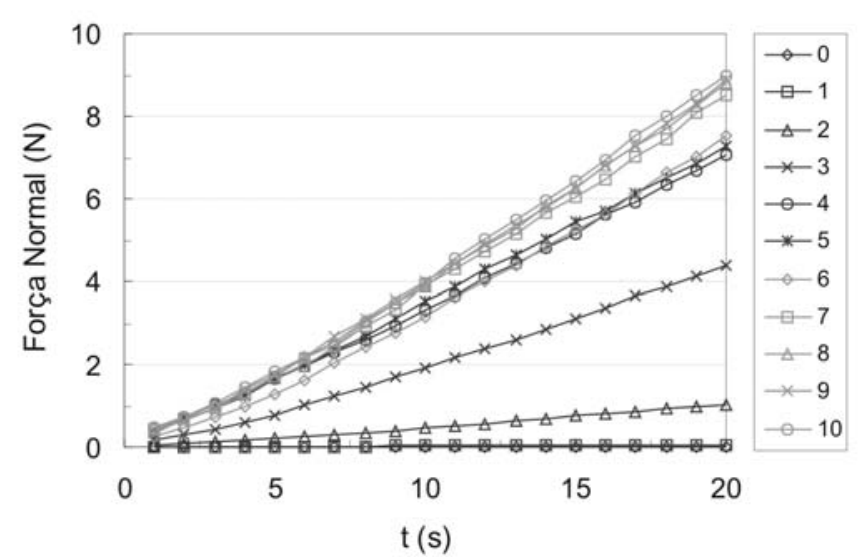

Figura 8: Força normal em função do tempo para amostras (0 a 10) de suspensão de alumina e sol de sílica com 0,3 peso\% de $\mathrm{MgO}$. [Figure 8: Normal force as a function of time for samples (0 to 10) of alumina and silica sol suspension with $0.3 \mathrm{wt} \% \mathrm{MgO}$.]

$\mathrm{m}^{2}$ de ácido cítrico como dispersante, com e sem adição de 0,6 peso\% de $\mathrm{MgO}$ (porcentagem em relação ao peso da suspensão de sílica). A suspensão que contém $\mathrm{MgO}$ foi ensaiada após gelificação, de maneira a determinar a tensão adequada de ensaio para uma amostra que se gelifique ao longo do tempo, mantendo-se sempre a solicitação dentro de seu regime elástico, independentemente das mudanças que possam ocorrer.

G' constante em função da tensão significa que o material está sendo solicitado dentro do regime elástico; oscilações significam que a tensão imposta desestruturou o material. O módulo permanece constante até aproximadamente $5 \mathrm{~Pa}$ para ambas as amostras, sendo assim, os ensaios de gelificação foram realizados em tensão constante de $1 \mathrm{~Pa}$, para garantir que a amostra esteja em regime elástico tanto antes como após sua gelificação e permitir a leitura de um sinal claro e intenso dessa propriedade. Com a determinação desse parâmetro, foram realizados os ensaios dinâmicos para verificação da ocorrência da reação de gelificação na suspensão base com variação do teor de adição de agente gelificante $\mathrm{MgO}$ e da temperatura de ensaio (vide Figs. 6 e 7).

Observa-se que com o acréscimo do teor de $\mathrm{MgO}$ e elevação da temperatura de ensaio, há uma diminuição do tempo necessário para aumento de ambos os módulos até o alcance de um valor constante (em torno de $\mathrm{G}^{\prime}=10^{6} \mathrm{~Pa}$ e G"= $10^{5} \mathrm{~Pa}$ ), indicando o fim da reação de gelificação. Fisicamente, a suspensão se torna mais elástica ao mesmo tempo em que aumenta sua capacidade de dissipar energia quando deformada, porém, o módulo de perda cresce em taxas menores e atinge valores cerca de uma ordem de magnitude menor que o módulo de armazenamento.

$\mathrm{Na}$ literatura são descritos vários métodos para se determinar o tempo de término da reação de gelificação, freqüentemente chamado ponto de gel [7]. Um dos critérios, por exemplo, prevê que o ponto de gel é

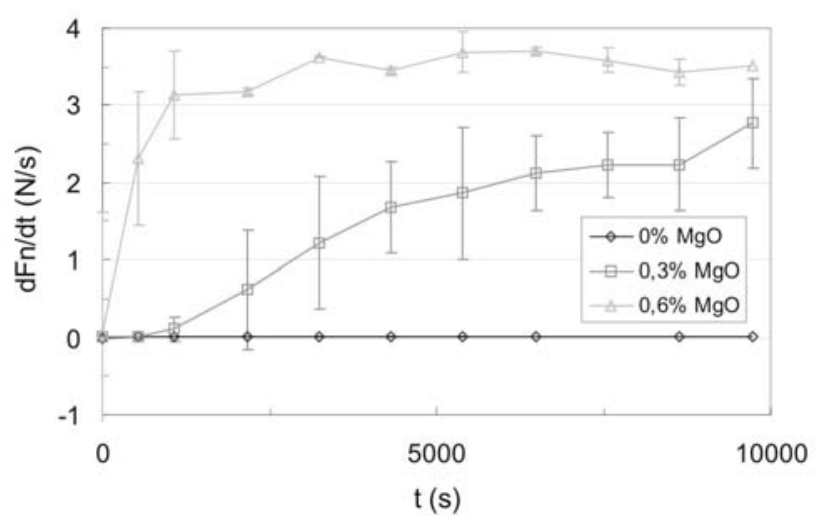

Figura 9: Taxa de força normal em função do tempo para suspensões de alumina e sol de sílica a $25^{\circ} \mathrm{C}$.

[Figure 9: Normal force rate as a function of time for alumina and silica sol suspensions at $25^{\circ} \mathrm{C}$.]

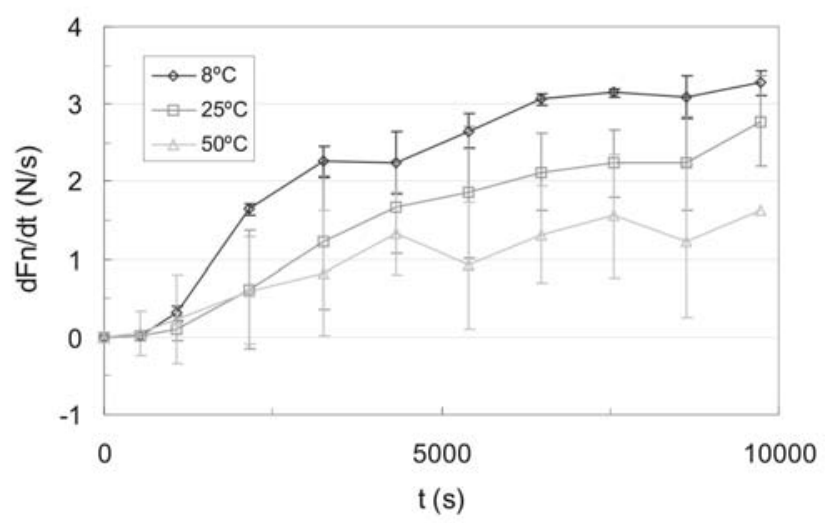

Figura 10: Taxa de força normal em função do tempo para suspensões de alumina e sol de sílica com 0,3 peso\% de $\mathrm{MgO}$.

[Figure 10: Normal force rate as a function of time for alumina and silica sol suspensions with $0.3 \mathrm{wt}$ \% $\mathrm{MgO}$.]

alcançado quando as curvas de G' e G" se interceptam. No entanto, no caso do sistema em estudo, em nenhum momento houve cruzamento entre as curvas. Como essas metodologias foram desenvolvidas a partir do estudo de reações de cura de resinas poliméricas, verifica-se que nem sempre podem ser aplicadas em suspensões cerâmicas.

Durante os ensaios oscilatórios, notou-se que o G' das amostras que se gelificavam atingiam um patamar próximo ao valor de $10^{6} \mathrm{~Pa}$. No entanto, apesar do aumento da elasticidade das suspensões, mesmo entre aquelas que atingiam $\mathrm{G}^{\prime}=10^{6} \mathrm{~Pa}$, algumas não possuíam rigidez suficiente para desmoldagem (verificado empiricamente com uma espátula), chegando até mesmo a fluir facilmente após desmoldagem. Assim, é razoável supor que embora seja adequado para indicar a ocorrência ou não da reação de gelificação, somente o módulo de 
armazenamento não será um parâmetro suficiente para determinar a resistência do material ao manuseio.

A necessidade da utilização de outra propriedade para determinação dessa rigidez levou à realização de ensaios de força normal, onde se mede a resistência do material a uma deformação axial imposta, ou seja, detecta-se a força normal gerada pela amostra em resposta à penetração da ferramenta, um indentador em forma de lâmina (Fig. 1e). Primeiramente, a suspensão a ser analisada é dividida em onze amostras ( 0 a 10 ) em recipientes que se encaixam no copo do reômetro Haake. São cobertas com óleo para evitar a secagem, tal como os ensaios de gelificação e mantidas em temperatura constante em uma câmara climática. Em intervalos de tempo regulares, ao longo de um período de $3 \mathrm{~h}$ (maior que o tempo para a gelificação das amostras) as amostras vão sendo, uma a uma, submetidas às medidas de força normal (cada amostra é ensaiada em um tempo de espera diferente após a mistura da suspensão). A ferramenta move-se com taxa de penetração de $1 \mathrm{~mm} / \mathrm{s}$ durante $20 \mathrm{~s}$. Essa taxa foi determinada por não promover a formação de trincas nas amostras, garantindo que o ensaio seja realizado dentro do regime viscoelástico do material. Desse modo, podese determinar em que momento a resistência mecânica adquirida pela suspensão é suficiente para desmoldagem sem danos à peça.

Foram ensaiadas as mesmas suspensões anteriormente submetidas aos ensaios de gelificação. Para cada condição, os ensaios foram realizados em duplicata e os valores obtidos de força normal em função do tempo de coleta para cada amostra foram derivados em função do tempo, gerando uma taxa de força normal, cuja média dos valores é apresentada em função do tempo total do ensaio. A Fig. 8 ilustra, como exemplo, curvas da força normal registrada para cada uma das amostras de uma suspensão em um ensaio em função do tempo de coleta de dados. As Figs. 9 e 10 apresentam a média da taxa de força normal em função do tempo total de ensaio.

Quanto maior o teor de $\mathrm{MgO}$ adicionado, mais rápido o aumento da taxa de força normal em função do tempo e maior o valor atingido, indicando um maior aumento da resistência à deformação da suspensão. A desmoldagem pode ser realizada quando a taxa de força normal se torna constante, o que significa que a suspensão atingiu a máxima resistência possível. Nesse sistema, apenas a suspensão com 0,6 peso\% de $\mathrm{MgO}$ atende essa condição, estando apta para a desmoldagem após 35 min, aproximadamente. Para as amostras com adição de 0,3 peso\% de $\mathrm{MgO}$ a taxa de força normal aumenta significativamente, mas não se estabiliza, ou seja, após o período de ensaio a suspensão ainda não atingiu a máxima resistência, não sendo possível desmoldá-la.

Verifica-se que a temperatura não influencia a taxa de força normal do mesmo modo que influencia os módulos G' e G'. Observa-se que a resistência à deformação é semelhante nas três condições de ensaios e que o aumento da temperatura gerou um aumento da dispersão dos dados, mas não acelerou a taxa de aumento da resistência mecânica.

O aumento da temperatura favorece a consolidação do sol de sílica por dois meios: a secagem da suspensão, que aproxima as partículas de sílica e pelo aumento da energia cinética dessas partículas, o que aumenta o número de colisões efetivas para a formação de ligações siloxano ( $\mathrm{Si}-\mathrm{O}-\mathrm{Si}$ ), que constituem o gel [6]. No entanto, nas condições experimentais utilizadas, não se permitiu a secagem das suspensões. Assim, pode ser que apenas o aumento da energia das partículas, sem a diminuição da quantidade de água presente, possa ter dificultado a formação de ligações siloxano, gerando a tendência observada de menores taxas de força normal para a temperatura de $50{ }^{\circ} \mathrm{C}$, seguidas das taxas para as temperaturas de 25 e $8{ }^{\circ} \mathrm{C}$.

Por fim, pode-se afirmar que há uma defasagem nas velocidades dos fenômenos (aumento de G' e elevação de resistência mecânica, obtida por meio da medida de força normal), que deve ser melhor investigada em estudos posteriores.

\section{CONCLUSÕES}

Os ensaios oscilatório e de força normal permitiram a obtenção de novas informações sobre os fenômenos que envolvem a gelificação no sistema alumina/sol de sílica, permitindo melhorar e entender seu processamento. Os módulos de armazenamento e de perda são indicativos da ocorrência e da cinética de gelificação do sol de sílica. Enquanto eles podem ser utilizados na determinação do tempo máximo para início de moldagem, a força normal descreve a evolução da resistência mecânica do corpo e pode ser um indicativo do tempo mínimo necessário para desmoldagem das peças.

\section{AGRADECIMENTOS}

Os autores agradecem à Alcoa Brasil pelo fornecimento das matérias-primas e à CAPES e à FAPESP pelo apoio à pesquisa.

\section{REFERÊNCIAS}

[1] H. N. Stein, Rheological Behavior of Suspensions, in N. P. Cheremisinoff, (Ed.) Encyclopedia of Fluid Mechanics: slurry flow technology, Gulf Publishing, Houston, vol. 5 (1986) 3-47.

[2] I. R. Oliveira, A. R. Studart, R. G. Pileggi, V. C. Pandolfelli, Dispersão e empacotamento de partículas princípios e aplicações em processamento cerâmico, Fazendo Arte Editorial, S. Paulo, Brasil (2000) 4.

[3] S. Banerjee, Am. Ceram. Soc. Bull. 77, 10 (1988) 59-63. 
[4] G. Schramm, A Practical Approach to Rheology and Rheometry, $2^{\text {nd }}$ Ed., Gebrueder HAAKE GmbH, Karlsruhe (1998) 119-121.

[5] J. Nijman, Introduction to Normal Stress, Catálogo Thermo Haake, 16 p.

[6] R. K. Iler, The Chemistry of Silica: solubility, polymerization, colloid and surface properties and biochemistry, John Wiley \& Sons, New York (1979) 172-439.

[7] J. M. Laza, C. A. Julian, E. Larrauri, M. Rodriguez, L. M. Leon, Thermal scanning rheometer analysis of curing kinetic of an epoxy resin: an amine curing agent, Polymer 40 (1998) 35.

(Rec. 25/05/2005, Ac. 24/06/2005) 